As noted previously, four of five high IQ age groups performed better than their low IQ counterparts. Results also support previous research with other illusions which contend that age may be an important determinant of the perception of visual stimuli. The older the child is, the more easily he is able to change visual perspectives.

In summary, this study supports the contention that age and IQ are linked to performance with the Necker cube. Because other studies on perceptual tasks have found similar results, it may be possible to infer that developmental and cognitive factors are important in determining results of visual receptual paradigms.

\section{REFERENCES}

Baer, D. J. Set and shock-stress effects upon illusion perception. Journal of Psychology, 1964, 467-472.

Fisichelli, V. R., Rockwell, R. V., \& Clark, L. The effects of electroshock on the rates of reversals of ambiguous perceptual figures. American Journal of Psychology, 1955, 68, 638-644.

Flavell, J. The developmental psychology of Jean Piaget. Princeton: Van Nostrand, 1963.

Hanley, C., \& Zerbolio, D. J. Developmental changes in five illusions measured by the up-and-down method. Child Developm ent, 1965, 35, 437-452.

Holt, G. L., \& Matson, J. L. Perceptual rigidity as a function of age in the Necker cube. Submitted, Human Development, 1974.

Jenkins, J., \& West, N. I. Perception in organic mental defectives; an exploratory study II. The Muller-Lyer illusion. School Bulletin, 1959, 55 .
Leibowitz, H. W., \& Judisch, J. The relationship between age and the magnitude of the Ponzo Illusion. American Journal of Psychology, 1967, 80, 105-109.

Necker, L. A. Observations on some remarkable phenomena seen in Switzerland and an optical phenomenon which occurs on viewing of a crystal or geometric solid. Philadelphia Magazine, Ser. 1, 1832, 3, 329-337.

Orbach, J., Ehrich, D., \& Heath, H. A. Reversability of the Necker Cube I: An examination of the concept of satiation of orientation. Perception \& Motor Skills, 1963, 16, 439-458.

Pickergill, M. J., \& Jeeves, M. A. The origin of the after effect of movement. Journal of Experimental Psychology, 1964, 15, 90-103.

Pollack, R. H. Contour detectability thresholds as a function of chronological age. Perceptual \& Motor Skills, 1963, 17, 411-417.

Pollack, R. H. Simultaneous and successive presentation of elements of the Muller-Lyer figure and chronological age. Perceptual \& Motor Skills, 1964, 19, 300-310.

Pollack, R. H. Temporal range of apparent movement as a function of age and intelligence. Psychonomic Science, 1966 , $5(6), 243-244$.

Roland, B. Relationships between G.S.R., heart rate, and reversibility of the Necker cube. Perceptual \& Motor Sills, $1970,30(1), 36-38$.

Spitz, H. H., and Lipman, R. S. Some factors affecting Necker cube reversal rates. Perceptual and Motor Skills, 1962, 15. 611-625.

Wapner, S., \& Werner, H. Perceptual development. Worchester, Massachusetts; Clark University Press, 1957.

Wapner, S. Werner, H. \& Comalli, P. E. Perception of part-whole relationships in middle and old age. Journal of Gerontology, $1960,15,413-415$.

(R eceived for publication August 5, 1974.)

\title{
Effects of location of response prevention upon extinction of instrumental avoidance in young and adult rats*
}

\author{
MARTIN J. MARRAZO $†$ and DAVID C. RICCIO \\ Kent State University, Kent, Ohio 44240
}

\begin{abstract}
Following acquisition of an avoidance response in a straight alley, young and adult rats received response prevention (blocking) either in the startbox or in the runway. For adults, both blocking locations yielded facilitated extinction compared with unblocked (regular extinction) controls, but blocking in the startbox was significantly more effective. In young Ss, only the startbox blocking condition reliably reduced later resistance to extinction.
\end{abstract}

Blocking (response prevention) of an active avoidance response has been shown repeatedly to produce a

* This investigation was supported in part by Grant GB 24220 from the National Science Foundation. A portion of this paper was presented at the meeting of the Eastern Psychological Association, Boston, April 1972. The authors acknowledge the kind assistance of Terrill Tharp and Michael Petras in collecting data. Requests for reprints should be sent to David C. Riccio, Department of Psychology, Kent State University, Kent, Ohio 44242 .

†Now at Psychological Services, VA Hospital, Albany, New York. substantial decrease in subsequent resistance to extinction of the locomotor response (e.g., Baum, 1970; Coulter, Riccio, \& Page, 1969; Page, 1955). In the area of appetitive conditioning, there is some evidence that, if an approach response is blocked, the subsequent resistance to extinction depends upon the location of response prevention (Lambert \& Solomon, 1952). Thus, it seemed of empirical interest to examine a similar possibility within the avoidance situation: Does the 
effectiveness of avoidance blocking depend upon the point in the response chain where prevention occurs? This problem cannot be readily examined with the two situations most commonly employed in studying response prevention, the jump-up chamber and the two-compartment avoidance apparatus. Accordingly, in the present study, avoidance training was conducted in a straight alley consisting of a startbox, runway section, and goalbox. The avoidance response was subsequently blocked either in the startbox or in the runway just before the goalbox.

A second aim of this study was to determine whether the response prevention manipulations facilitate avoidance extinction in young as well as in adult rats. There is reason to believe that age differences may exist in the effectiveness of blocking, since a recent study from our laboratory using a two-chamber task found no evidence of facilitated extinction in weanlings under conditions which clearly produced the phenomenon in adults (Marrazo, Riccio, \& Riley, 1974).

\section{METHOD}

\section{Subjects}

Thirty immature (22-23 days old) and 30 adult (90-120 days) male rats, purchased from Holtzman Company, Madison, Wisconsin, were randomly assigned to one of three treatment conditions $(\mathrm{N}=10$ per group). Adults were hou sed in gang cages with six to eight animals per cage and weanlings were housed in litters of six to eight Ss, with food and water available on an ad lib basis for both age groups.

\section{Apparatus}

The apparatus has been described in detail previously (see Riccio \& Marrazo, 1972). A 100-cm clear Plexiglas straight alley was divided into a startbox, runway, and goalbox by clear Plexiglas guillotine doors. A matched impedance shock source delivered a 200-V shock to the grid floor. [Campbell (1967) has shown that this particular shock source provides equally aversive stimulation for weanling and adult rats over a wide range of shock intensities.] The opening of the startbox door and the simultaneous onset of a Foringer click generator set at 5 clicks/sec provided the CS.

\section{Procedure}

A 2 by 3 factorial design was employed, with age (young or adult) and type of treatment (extinction controls, startbox blocking, or runway blocking) as factors.

Avoidance Training Procedure. All Ss received oneway escape-avoidance training in exactly the same manner. Previous to the first training trial, each $\mathrm{S}$ was given $2 \mathrm{~min}$ free access to explore the entire runway. The $S$ was then replaced in the startbox and the first trial was initiated. Onset of the click generator (CS) occurred simultaneously with the raising of the guillotine doors. The CS was followed $5 \mathrm{sec}$ later by a $200-\mathrm{V}$ scrambled shock (UCS) delivered to the startbox and runway grid floor. When the $\mathrm{S}$ entered the goalbox, a photocell beam was broken, thereby terminating both CS and UCS. Each trial was separated by a 60 -sec intertrial interval, during which the animal remained in the goalbox. Active avoidance training was terminated when the $\mathrm{S}$ completed five consecutive avoidances.

Extinction Controls. For the regular extinction groups, no further shock was administered after avoidance criterion was met. Test trials were continued until the $\mathrm{S}$ did not enter the goalbox on five consecutive trials or until 50 extinction trials had been completed. A trial was arbitrarily terminated $10 \mathrm{sec}$ after CS onset if $S$ had not entered the goalbox. Thus, an extinction response could consist of remaining in the startbox or entering the runway. The same criterion of extinction was also employed for the blocked groups. During extinction Ss were removed from the goalbox and placed in a retainer cage for the intertrial interval.

Startbox Blocked Group. After meeting avoidance criterion, animals in these groups received five trials, during which the CS was presented without shock for $10 \mathrm{sec}$. On each of the trials, the $\mathrm{S}$ was prevented from leaving the startbox by the clear Plexiglas door. Subsequent to the five blocked trials, testing was continued as in regular extinction testing, with both doors being raised at the onset of each trial. During the blocking phase and during the extinction phase, the $\mathrm{S}$ was placed in a retaining cage for the intertrial interval.

Runway Blocked Group. Subsequent to avoidance training, weanlings and adults in this condition received five trials, during which only the CS was presented for $10 \mathrm{sec}$. However, Ss were not prevented from leaving the startbox. Instead, when they ran down the runway, entrance to the goalbox was blocked by a clear Plexiglas door. As with the other blocked group, these Ss were then tested as in regular extinction until cessation criterion was met.

\section{RESULTS}

Since all Ss were treated alike during acquisition of active avoidance, the data for the weanling groups was pooled and compared with the pooled adult data by means of a $t$ test. The mean number of trials to criterion for weanlings and adults was 12.6 and 9.8, respectively. Results of a $t$ test indicated that the weanlings needed significantly more trials to reach avoidance criterion than did adults $(t=2.679, p<.01)$. Additionally, an analysis of variance performed on the data failed to show any within-age differences in trials to criterion for the three weanling $(\mathrm{F}=.97, \mathrm{df}=2 / 27, \mathrm{p}>.10)$ and three adult groups $(F=1.47, \mathrm{df}=2 / 27, \mathrm{p}>.10)$.

The mean number of trials to cessation of the avoidance response is shown in Fig. 1. Analyses of variance on the data ${ }^{1}$ revealed a significant effect of age $(\mathrm{F}=5.161, \mathrm{df}=1 / 54, \mathrm{p}<.03)$ and a highly significant treatment effect $(F=23.70, \mathrm{df}=2 / 54, \mathrm{p}<.0001)$, as well as a significant Age by Treatment interaction $(F=6.79, \quad d f=2 / 54, \quad p<.003)$. Newman-Keuls comparisons of means indicated that the startbox blocked weanling and adult groups extinguished significantly quicker than their respective extinction control groups (both ps $<.05$ ). Also, adults blocked in the runway met cessation criterion significantly quicker than adult controls $(p<.05)$, but runway blocked weanlings did not differ significantly from the weanling control group $(p>.05)$. Therefore, relative to control rats, runway blocking was not effective in reducing trials to cessation in weanling rats, although it was effective with adults. When the two blocking treatments were compared, it was found that startbox blocking was significantly stronger than runway blocking in reducing resistance to extinction in adults $(p<.05)$, but there 


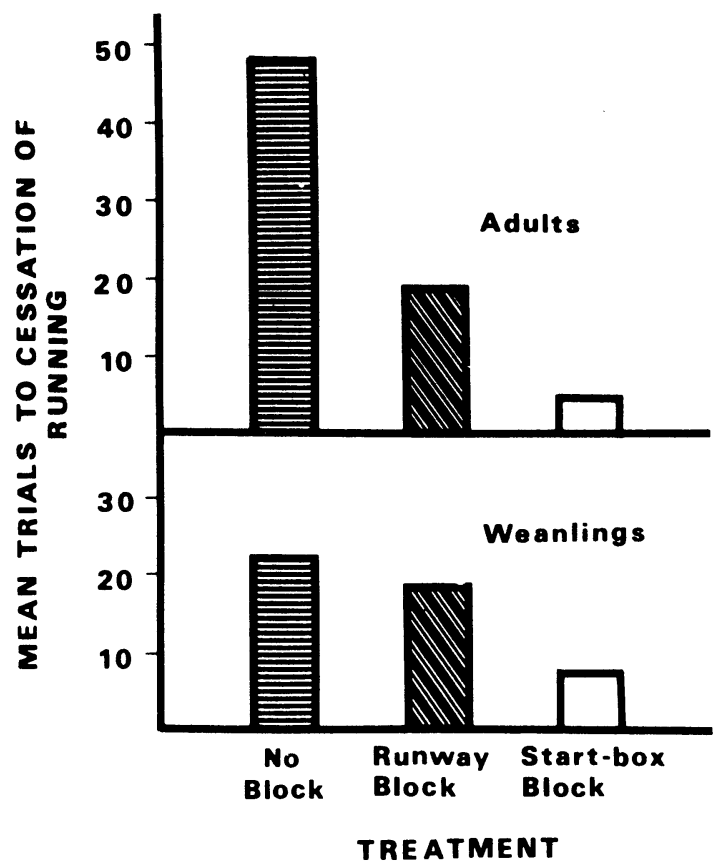

Fig. 1. Effects of location of response blocking upon resistance to extinction in young and adult rats.

was only a tendency of such an effect in weanlings $(\mathrm{p}<.10)$. Of ancillary interest was the fact that adults in the extinction control group exhibited significantly more avoidance responses during extinction than did immature controls $(p<.05)$. This finding occurred despite the fact that both age groups were trained to the same avoidance criterion and even though the weanlings received more CS-UCS pairings during avoidance training.

\section{DISCUSSION}

Response prevention given in the startbox is clearly more effective in hastening extinction of the locomotor avoidance response than the same duration of treatment provided in the runway. One possible interpretation of this finding is based on response compatibility. It has previously been suggested that during blocking Ss adventitiously acquire a new response which later interferes with instrumental avoidance behavior (Coulter et al, 1969). Accordingly, prevention in the startbox might be expected to produce a response highly incompatible with later running into the goalbox. Response prevention in the runway, while not permitting the $S$ to enter the goalbox, did allow forward running to occur and, therefore, provided a response less incompatible with the criterion behavior. This view is generally consistent with the finding (Adelman \& Maatsch, 1955) that the nature of the response that occurs during extinction plays an important role in determining resistance to extinction. Alternatively, the effects of the location of blocking could be based upon differences in Pavlovian extinction of fear. During avoidance training, rats received far more shock onsets in the start compartment than in the runway. Under these conditions, stimuli associated with the startbox presumably come to play a major role in controlling the initiation of responding. The differential blocking effects would reflect the degree of extinction to the relevant cues, i.e., animals blocked in the startbox had more nonreinforced exposure to cues previously associated with UCS onset, which in turn more effectively reduced their tendency to run during regular ex tinction trials.

The data also indicate that there are age-related differences in the effectiveness of the blocking procedures. For adults, the location of blocking influenced the degree of facilitated extinction, but both conditions attenuated avoidance responding. In contrast, young rats showed facilitated extinction only after being blocked in the startbox. This finding is especially striking, since baseline resistance to extinction was weaker in young than adult Ss. Thus, immature rats might be presumed to be more, not less, susceptible to blocking effects. The relative ineffectiveness of response prevention in young Ss here, in conjunction with the failure of weanlings to show facilitated extinction following blocking in a two-chamber apparatus (Marrazo et al, 1974), appear consistent with other data indicating deficits in the ability of immature animals to learn to withhold responding (cf. Riccio, Rohrbaugh, \& Hodges, 1968; Campbell, Riccio, \& Rohrbaugh, 1971). For example, when punishment is introduced in the goalbox following active avoidance training in a straight alley, young rats continue running into the goalbox longer than do adults (Riccio \& Marrazo, 1972). Whether the age-related differences in suppressing responding under these different experimental paradigms reflects a common mechanism is not yet clear.

\section{REFERENCES}

Adelman, H, M \& Maatsch, J, L, Resistance to extinction as a function of the type of response elicited by frustration Journal of Experimental Psychology, 1955, 50,61-65.

Baum, M. Extinction of avoidance responding through response prevention (flooding). Psychological Bulletin, 1970, 74, 276-284.

Campbell, B. A. Learning in infra-primate mammals. In $\mathbf{H}$. W. Stevenson, E. H. Hess, and H. L. Rheingold (Eds.), Early behavior. New York: Wiley, 1967.

Campbell, B. A., Riccio, D. C., \& Rohrbaugh, M. Ontogenesis of learning and memory: Research and theory. In M. Meyer (Ed.), Early learning. Bellingham: Western Washington University Press, 1971.

Coulter, X., Riccio, D. C., \& Page, H. A. Effects of blocking an instrumental avoidance response: Facilitated extinction but persistence of "fear.' Journal of Comparative \& Physiological Psychology, 1969, 68, 377-381.

Lambert, W. W., \& Solomon, R. L. Extinction of a running response as a function of block point from the goal. Journal of Comparative \& Physiological Psychology, 1952, 45, 269-279.

Marrazo, M. J., Riccio, D. C., \& Riley, J. Effects of Pavlovian CS-UCS pairings during avoidance response-prevention trials in rats. Journal of Comparative \& Physiological Psychology, $1974,86,96-100$.

Page, $\dot{H}$. $A$. The facilitation of experimental extinction by response prevention as a function of the acquisition of a new response. Journal of Comparative \& Physiological Psychology, 1955, 48, 14-16.

Riccio, D. C., \& Marrazo, M. J. Effects of punishing active avoidance in young and adult rats. Journal of comparaive $\alpha$ Phvsiological Psychology, 1972, 79, 453-458.

Riccio, D. C., Rohrbaugh, M., \& Hodges, L. A. Developmental aspects of passive and active avoidance learning in rats. Developmental Psychobiology, 1968, 2, 108-111.

\section{NOTE}

1. Since the five blocked trials constituted the treatment manipulation they were not included in the analysis of the extinction trials. It could be argued that the blocked trials should be added to the total trials required for the experimental groups to reach extinction criterion. We doubt that this alternative is appropriate, since CS exposure on a blocked trial is much longer than during a regular extinction trial and, in addition, the $\mathrm{S}$ had no control over CS termination; however, inclusion of blocked trials does not substantially alter the present results (treatment: $\mathrm{F}=13.17$, df $=2 / 54, \mathrm{p}<.0001$; Age by Treatment: $F=4.94$, $\mathrm{df}=2 / 54, \mathrm{p}<.02$ ).

(Received for publication August 16, 1974.) 